\title{
IMMEDIATE POSTOPERATIVE CARE, WITH PARTICULAR REFERENCE TO BLOOD-GAS STUDIES
}

\author{
C $\mathbb{R}$ Stephen, $\mathbf{D} \mid$ and I Talton, $M D^{*}$
}

WITH INCREASED STANDARDS of training, and improvements in anaesthetic techniques and drugs, anaesthetists now pride themselves that patients can usually be brought successfully through the most difficult of operative procedures Where problems arise in gieater incidence is in the immediate postoperative period It is here that the anaesthetist must play an even more active role in the future than he is doing at present

Recovery rooms, or postanaesthetic areas, which allow postoperative patients to be cared for by specially traned nurses, were an outgrowth of the Second World War Our responsibility as anclesthetists in this area was pointed out early by Dripps and Waters, who emphasized, in a connotation called the "Strr-up" regime, the importance of twinng the patient frequently, having him cough at regular intervals, and urging him to breathe deeply ${ }^{1}$ Recognizing the difficulty of obtaining the co-operation of the patient to breathe deeply, they suggested the intermittent inhalation of carbon dioxide, an idea which in recent years has made every anaesthetist recoil in horror They also recommended the continuous administration of oxygen, where indicated, by means of a catheter inserted through the nose into the oropharynx, a technique which has stood the test of time

In the last 20 years, the role of adequate ventilation postoperatively has been stressed, with particular emphasis on carbon dioxide elımination Mechanical ventilators have been developed, and the indications for their use have mult1plied as the importance of preserving gas exchange to and from the lungs has been recognized Hand in hand with this alertness has been the development of objective means of determining the efficacy of respiratory exchange Reliable laboratory tests, which are not technically difficult to perform, have allowed us for several years to determine the $\mathrm{pH}$ and carbon dioxide tension, more or less at the bedside With special equipment at has also been possible to determine the arterial oxygen saturation But the saturation merely indicates how much oxygen is being carried in the blood as a percentage of that which the blood is capable of carrying under normal curcumstances, A much more accurate measurement is the oxygen tension, which indicates the partial pressure of oxygen in the arterial blood, and therefore the avarlability or ease with which oxygen can be presented to the tissues Within the last two to three years, as a result of the development of oxygen electrodes, it has for the first time become possible to measure under clinical circumstances the oxygen tension existing in blood This breakthrough is of vital importance in the care of patients

This paper is concerned primarnly with the arterial oxygen tensions found in

"Division of Anesthesiology, Duke Unıversity Medical Center, Durhain, North Caiolina

Can Anaes Soc J, vol 11, no 6, November, 1964 
patients in the immediate postoperative period these determinations have been correlated with the ability of patients to eliminate carbon dioxide It is important finst to determine what the normal arterial oxygen tension is The textbooks of physiology have told us that this figure is $100 \mathrm{~mm} \mathrm{Hg}$ with the patient breathing room aur However, Lambertsen ${ }^{2}$ indicates that the noimal value for arterial oxygen tension is $95 \mathrm{~mm} \mathrm{Hg}$ More recently Raine and Bıshop ${ }^{3}$ have shown that age and position are factors in the normal values for oxygen tension In subjects less than 40 years of age, the mean arterial oxygen tension while breathing air was $976 \mathrm{~mm} \mathrm{Hg}$ in the sitting position and $953 \mathrm{~mm} \mathrm{Hg}$ in the supine position In subjects over 40 years of age, the mean $\mathrm{paO}_{2}$ was $900 \mathrm{~mm} \mathrm{Hg}$ in the sitting posture and $882 \mathrm{~mm} \mathbb{H g}$ while supine In our own institution, the arterial oxygen tension in 14 patients whlle lying supine in the ward awaiting elective surgical procedures averaged $804 \mathrm{~mm} \mathrm{Hg}$, with a 1 ange between $100 \mathrm{~mm} \mathrm{Hg}$ in a 28-year-old patient to $575 \mathrm{~mm} \mathrm{Hg}$ in a 68-year-old patient (Table $\mathbb{I}$ ) The average age of these patients was 473 years, with a range between 28 and 68 years It is apparent that the "normal" arterial oxygen tension is unknown, and indeed may vary from patient to patient

IABLE 1

\begin{tabular}{|c|c|c|c|c|c|}
\hline & Age & Sex & $\mathrm{pH}$ & $\begin{array}{c}\mathrm{paCO}_{2} \\
(\mathrm{~mm} \mathrm{Hg})\end{array}$ & $\underset{\left(\mathrm{mm} \mathrm{paO}_{2}\right.}{\left.\mathrm{pg}^{2}\right)}$ \\
\hline 1 & 28 & $\mathrm{~F}$ & 740 & 432 & 931 \\
\hline 2 & 28 & F & 742 & 307 & 1000 \\
\hline 3 & 38 & $\mathrm{~F}$ & 741 & 396 & 874 \\
\hline 4 & 39 & $\mathrm{M}$ & 743 & 364 & 632 \\
\hline 5 & 45 & $F$ & 744 & 356 & 701 \\
\hline 6 & 46 & i & 746 & 304 & 747 \\
\hline 7 & 46 & $F$ & 739 & 392 & 885 \\
\hline 8 & 46 & F & 744 & 373 & 931 \\
\hline 9 & 48 & $\mathrm{~F}$ & 746 & 434 & 747 \\
\hline 10 & 51 & $\mathrm{M}$ & 744 & 373 & 759 \\
\hline 11 & 55 & $\mathrm{M}$ & 739 & 413 & 713 \\
\hline 12 & 60 & $\mathrm{M}$ & 742 & 448 & 805 \\
\hline 13 & 64 & $F$ & 741 & 372 & 966 \\
\hline 14 & 68 & M & 740 & 372 & 575 \\
\hline $\mathrm{Av}$ & 473 & & 742 & 381 & 804 \\
\hline
\end{tabular}

In our hospital random determinations of blood-gas values during and after operation in over 200 patients indicated that great variations could occur, depending on the physical status of the patient, the type of operation being performed, and the care with which the anaesthetic was being administered It became obvious that adequate elimination of carbon dioxide from the lungs did not necessarily ensure a normal arterial oxygen tension, thus perhaps reaffirming the old physiological doctrine that it is 20 times easier to get carbon dioxide across the alveolar membrane than it is oxygen For example, in a 77-year-old woman undergoing subtotal gastric resection ( $F_{1} g$ 1), it was not possible to obtain a normal arterial oxygen tension, even though ventilation was sufficient to produce a definite respiratory alkalosis In another, patıent, a 23-year-old man having a closure of a transverse colostomy $\left(\mathbb{F}_{1} g 2\right)$, oxygen tensions were above normal during operation, but when he was allowed to breathe room air in the 
Age 77 W F

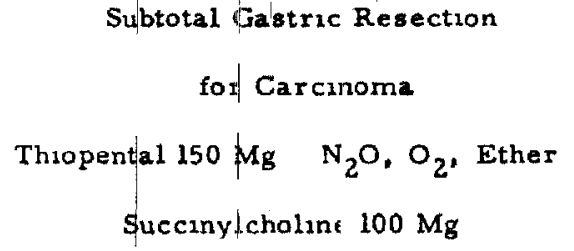

The $\quad \begin{array}{lll}\mathrm{pH} & \mathrm{pCO}_{2} & \mathrm{pO}_{2}\end{array}$

$144 \quad 748 \quad 345$

200

205

185

170

175

762
50

60

56

67

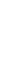

0

60

51

67

$$
\begin{aligned}
& \text { Beginning Suligery } \\
& \text { Spon Resp } \\
& \text { B P } 160 / 90 \\
& \text { Cont Resp } \\
& \text { B P } 120 / 80 \\
& \text { Cont Resp } \\
& \text { B P } 120 / 80 \\
& \text { Cont Resp } \\
& \text { B P } 140 / 80 \\
& \text { Cont Resp } \\
& \text { B P } 160 / 90 \\
& \text { Cont Resp } \\
& \text { B P } 180 / 100^{-} \\
& \text {C }
\end{aligned}
$$

Figure 1 Artenal blood-gas values in a 77-year-old womah undergoing subtotal gastric resection Note low arterial oxygen tensions in presence of induced respiratory alkalosis

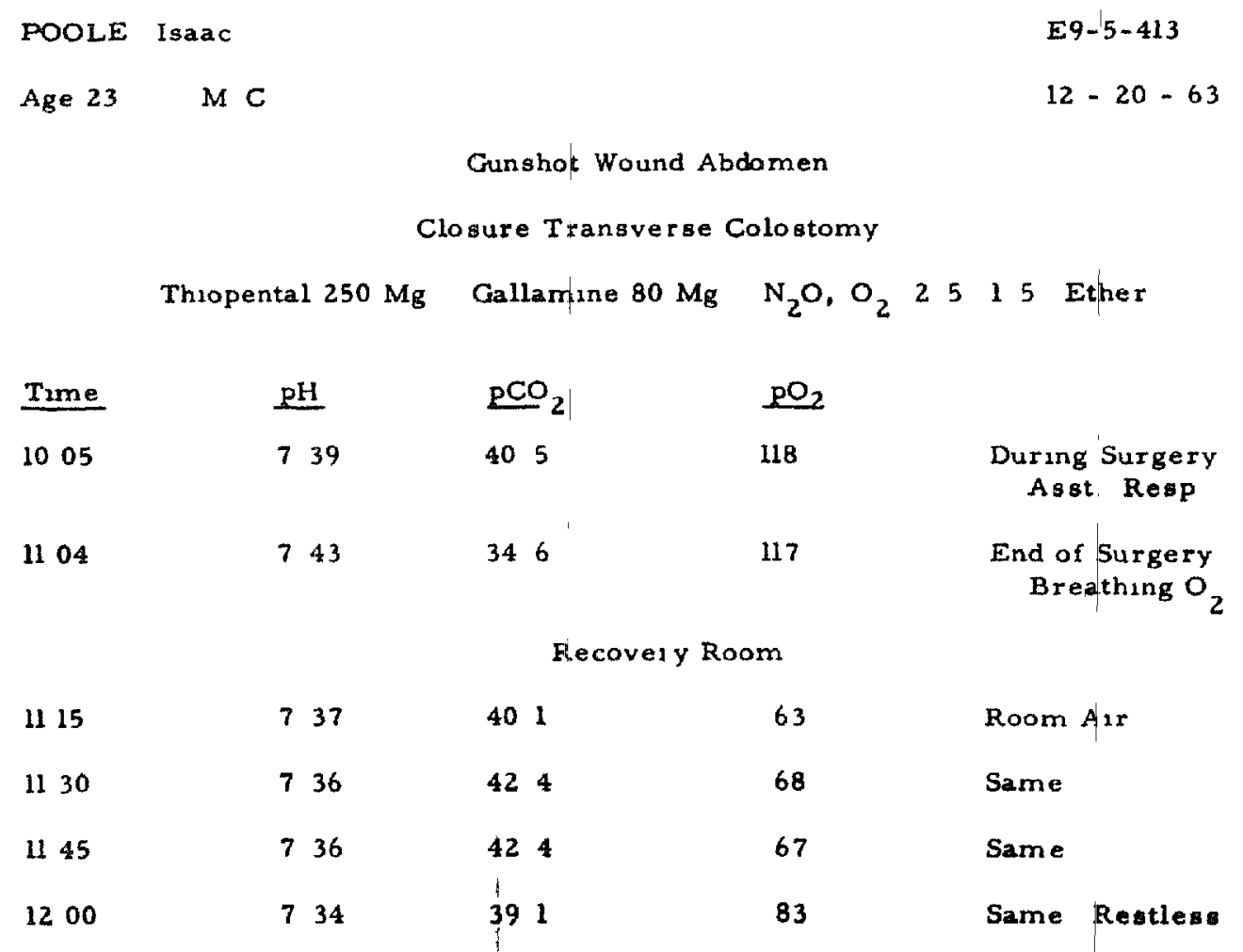

Figure 2 Arterial blood-gas values in a 23-year-old man having a closure of a transverse colostomy Note reduction in arterial oxygen tensions in recovery room in spite of preservation of normal acid-base balance

recovery room, the arterial oxygen ten\$1on was reduced to low levels, even though the $\mathrm{pH}$ and carbon dioxide tensions remained within normal limits

For these reasons an objective study was undertaken to determine what happened to patients postoperatively. 
Respiration By means of a Wright Respirometer and a Bennett face-mask, respiratory rates, tidal volumes, and minute volumes were determined in 20 patients the afternoon before operation (control), immediately on arrival in the recovery room, and at 10 and 30 minute intervals in the recovery room All types of general anaesthesıa were used, including ethyl ether, cyclopropane, halothane, and methoxyflurane, and the same physician performed all the measurements Oxygen was not administer ed to this control group The average minute volume preoperatively was 60 litres, and three readings postoperatively differed little (Fig 3) The average respiratory rate before operation was 17

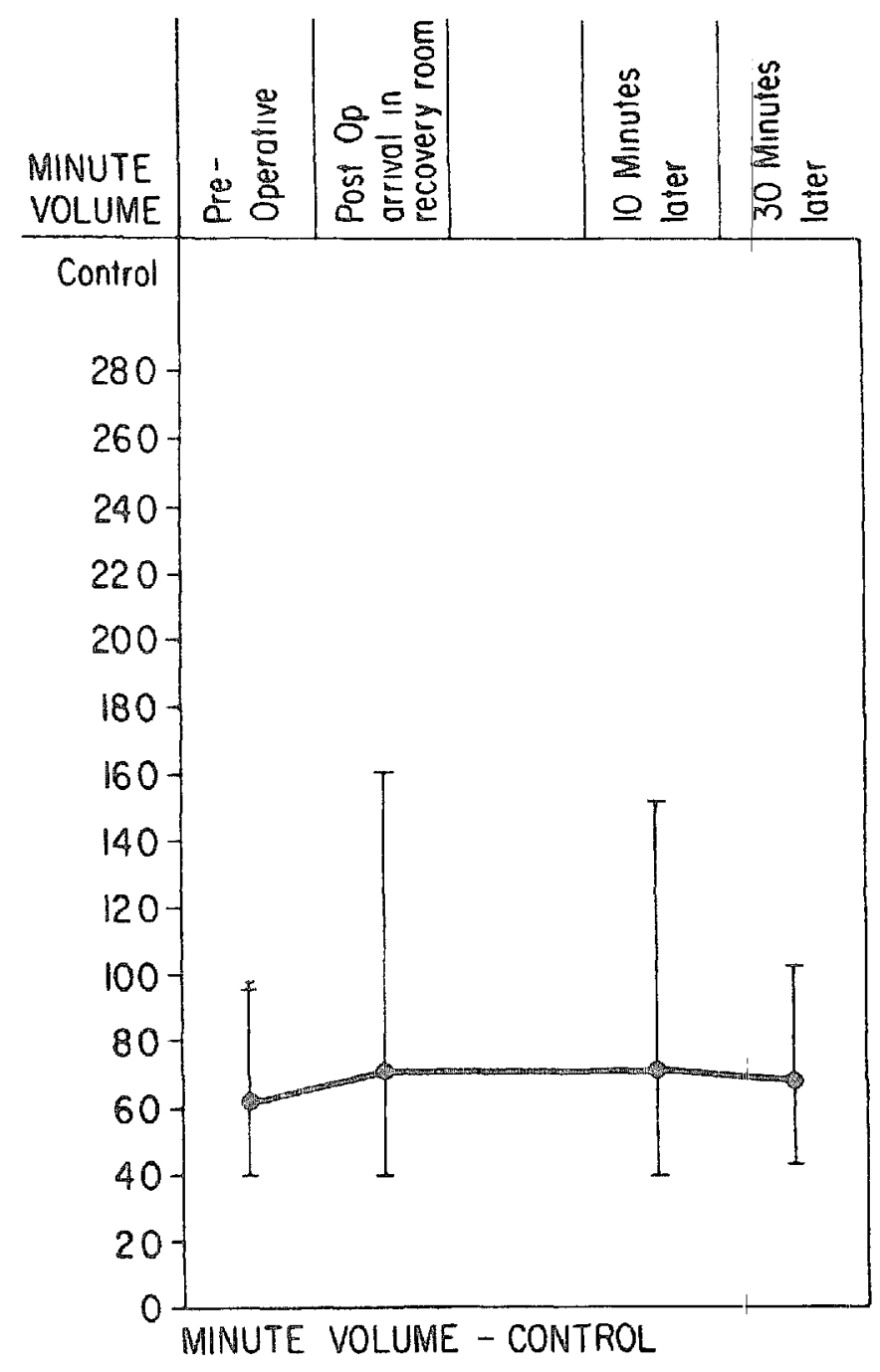

Figure 3 Minute volumes (average and extremes) in 20 patients the day prov to operation, and in the immediate postoperative period

per minute, and the average tidal volume was $350 \mathrm{ml}$ These values were essentrally unaltered in the postoperative period (Figs 4 and 5) Under the circumstances of this study, respinatory parameters were not grossly altered by anaesthesia and operation

Blood gas values During anaesthesia an arterial needle was placed in the radial, ulnar, or brachial artery, and blood samples were withdrawn at various intervals in heparnized syrunges under anaerobic conditions Within 5 to 10 minutes of obtaining the sample, determinations of $\mathrm{pH}$, carbon droxide tension, and oxygen tension were made, always by the same technıcian, on an Instrumentation Laboratones apparatus Corrections were made for body temperature and haematocrit 


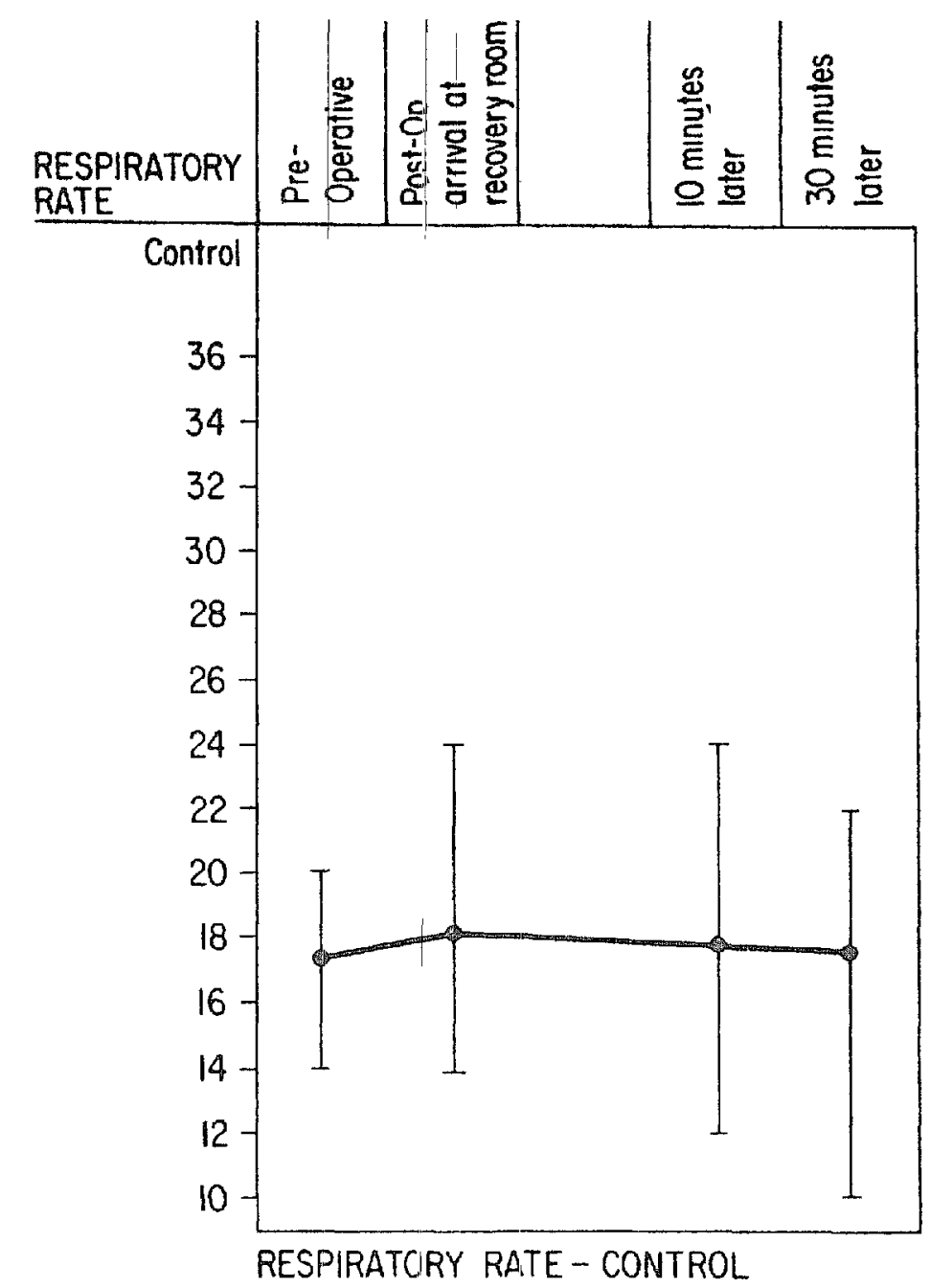

Figure 4 Respuratory rates (average and extremes) in 20 patients the day before surgery and in the immediate postoperative period

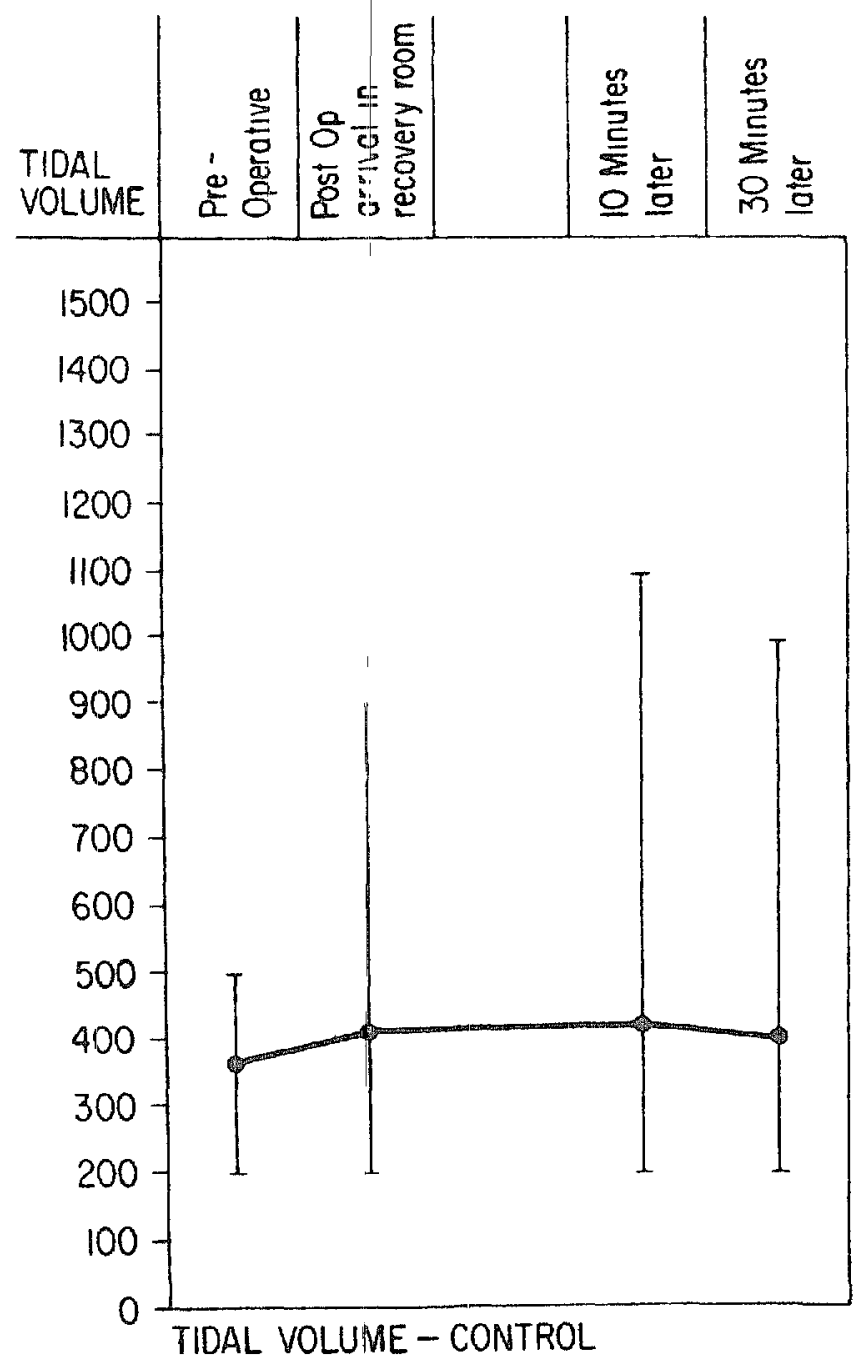

Figure 5 Tidal volume (average and extremes) the day belore surgery and in the immediate posloperative period 


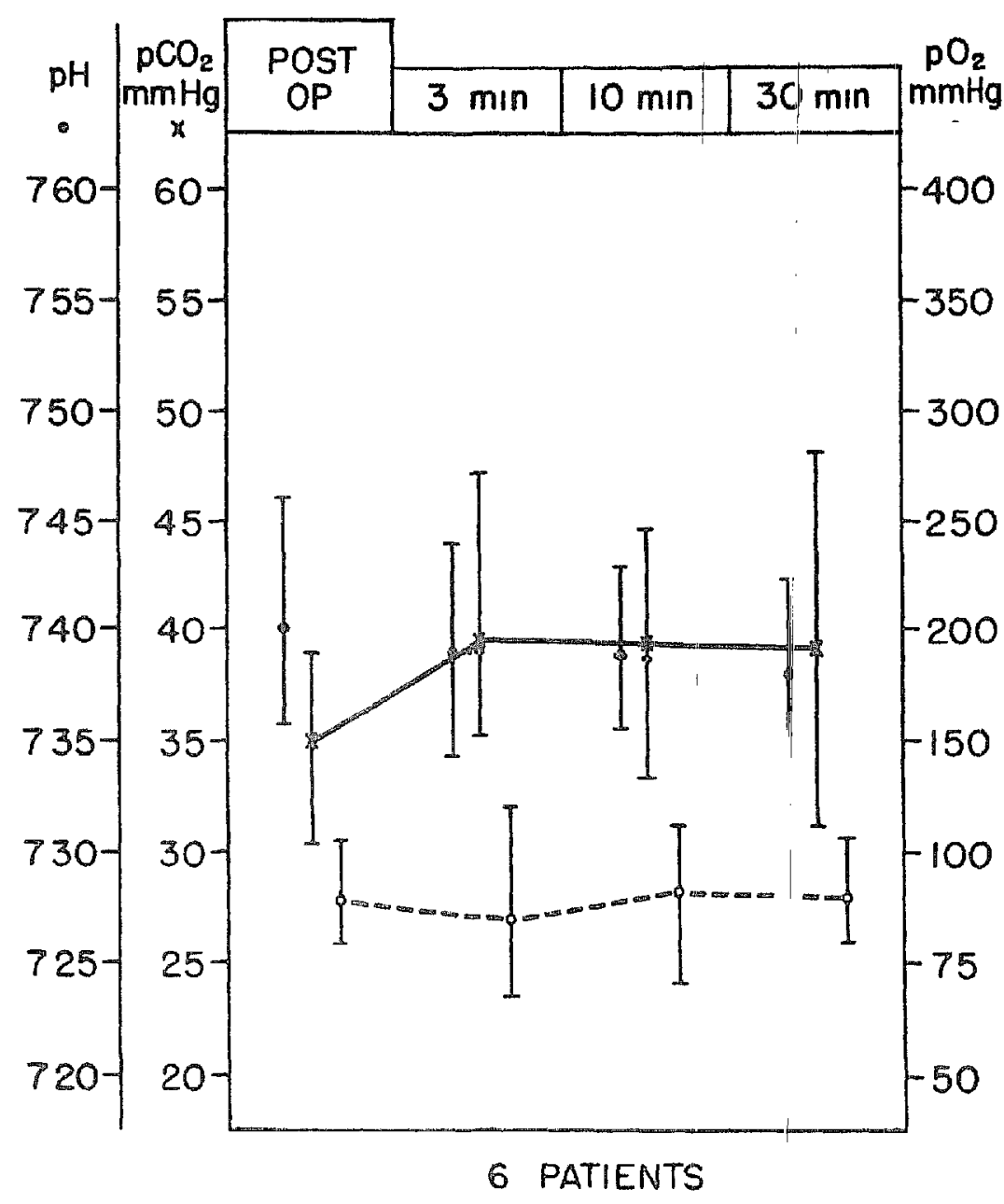

Figure $6 \mathrm{pH}, \mathrm{paCO}_{2}$, and $\mathrm{paO}_{2}$ values in $\mathrm{six}$ patients who did not receive oxygen postoperatively Note normal acid-base balance, but evidence of arterial hypoxaemia

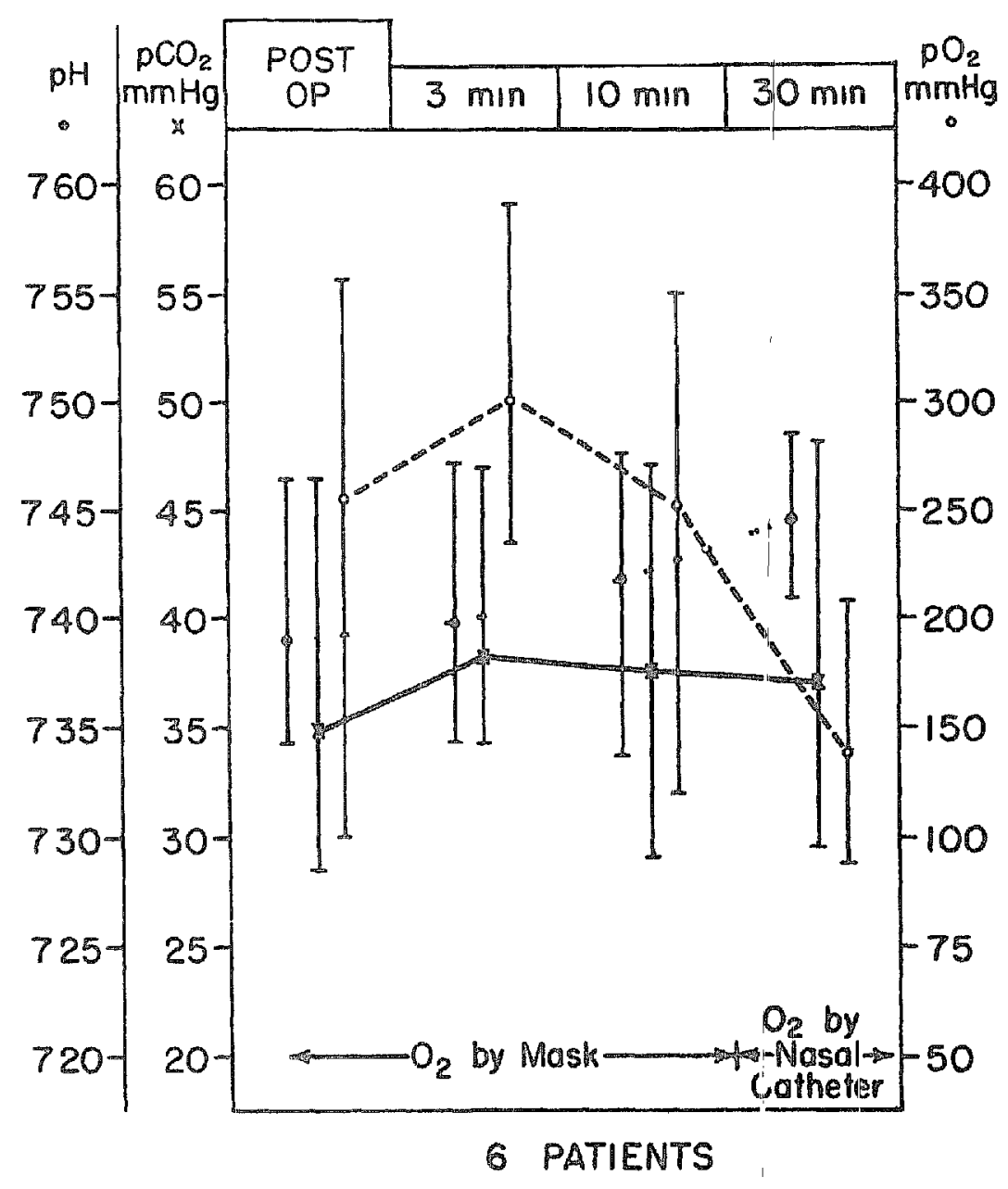

Figure $7 \mathrm{pH}, \mathrm{paCO}_{2}$, and $\mathrm{paO}_{2}$ values in six patients who received oxygen in postoperative period Note normal acid-base balance and satisfactory oxygen tension values 
In 6 patients followed postoperatively for 30 minutes, in whom a vigorous stir-up regime was maintained, but to whom no oxygen was given, the $\mathrm{pH}$ and $\mathrm{paCO}_{2}$ were essentially within normal limits, but the $\mathrm{paO}_{2}$ (average) was in the range of $80 \mathrm{~mm} \mathbb{H g}$ ( $F$ ig 6) A second similar group of patients to whom oxygen was administered, first by bag and mask and then by nasal catheter, showed marked increases in oxygen tension (Fig 7) The pHI and $\mathrm{paCO}_{2}$ values remained within normal limits

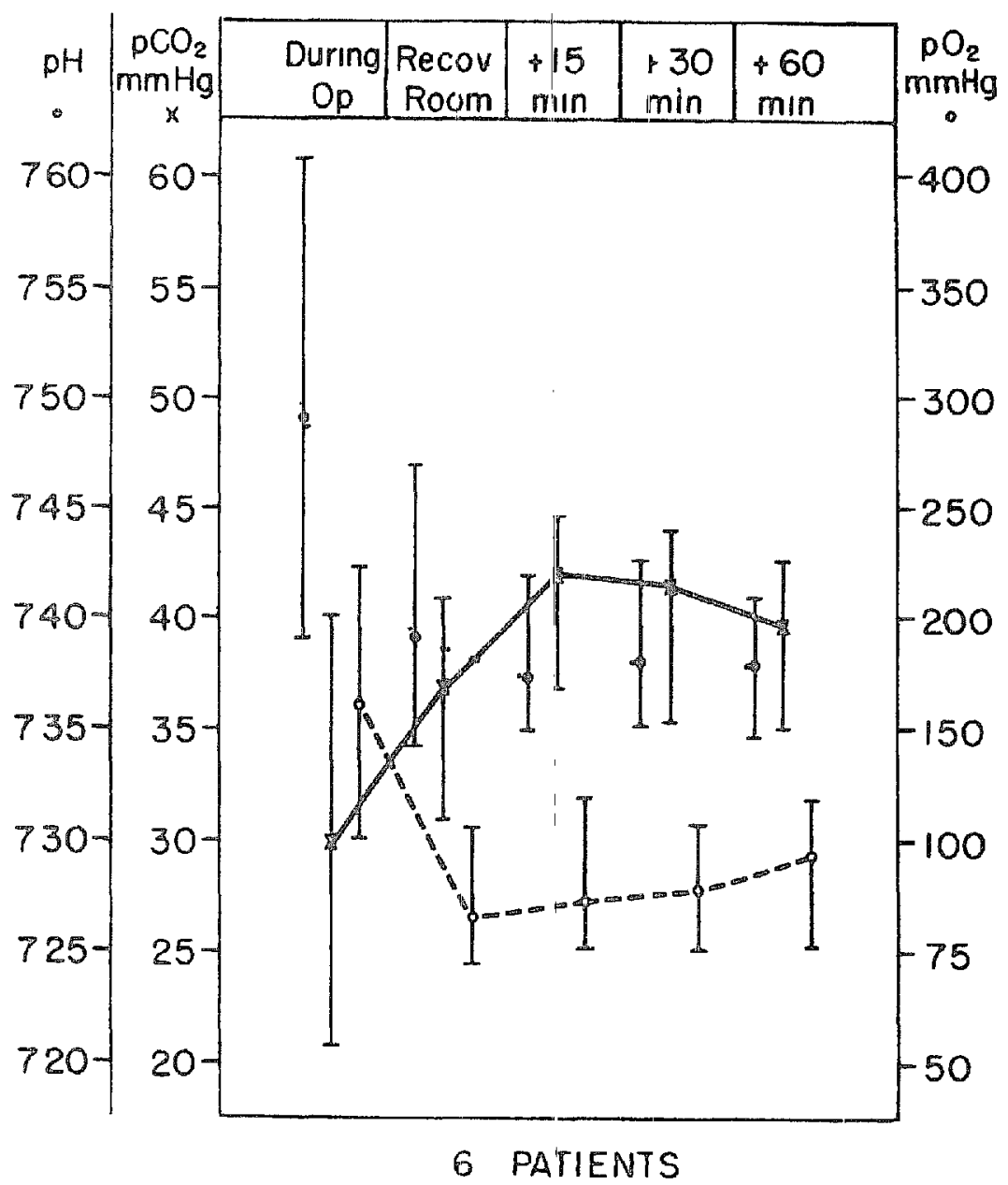

Figure $8 \mathrm{pH}, \mathrm{paCO}_{2}$, and $\mathrm{paO}_{2}$ values obtamed in six patents during anaesthesia and for 60 minutes in postoperative period patuents did not receive oxygen postoperatively Note normal acid-base values, but artenal hypoxaemia postoperatively

In a third group of 6 patients (Fig 8), who were followed for 60 minutes postoperatively, an arterial blood sample was taken while under anaesthesia Durning surgery the average $\mathrm{pH}$ was 748 , the $\mathrm{paCO}_{2}$ was $30 \mathrm{~mm} H \mathrm{Hg}$, and the $\mathrm{paO}_{2}$ was $160 \mathrm{~mm} \mathrm{Hg}$ It would appear that these patients were beng adequately ventilated and oxygenated durng anaesthesia However, in the postoperative period, although the $\mathrm{pH}$ and $\mathrm{paCO}_{2}$ values were within normal limits, arterial hypoxaemia was again present Over a period of one hour there was a gradual uncrease in the $\mathrm{paO}_{2}$, and at 60 minutes it was approaching normal values

A fourth group of 8 patients were also followed for 60 minutes alter operation, but oxygen by nasal catheter ( 6 to 7 litres per minute) was begum on arrival in the recovery room ( $F i g 9)$ These patients again were able to eliminate carbon dioxide satusfactorly, and the additıonal oxygen provided served to maintain a satusfactory oxygen tension in most instances 


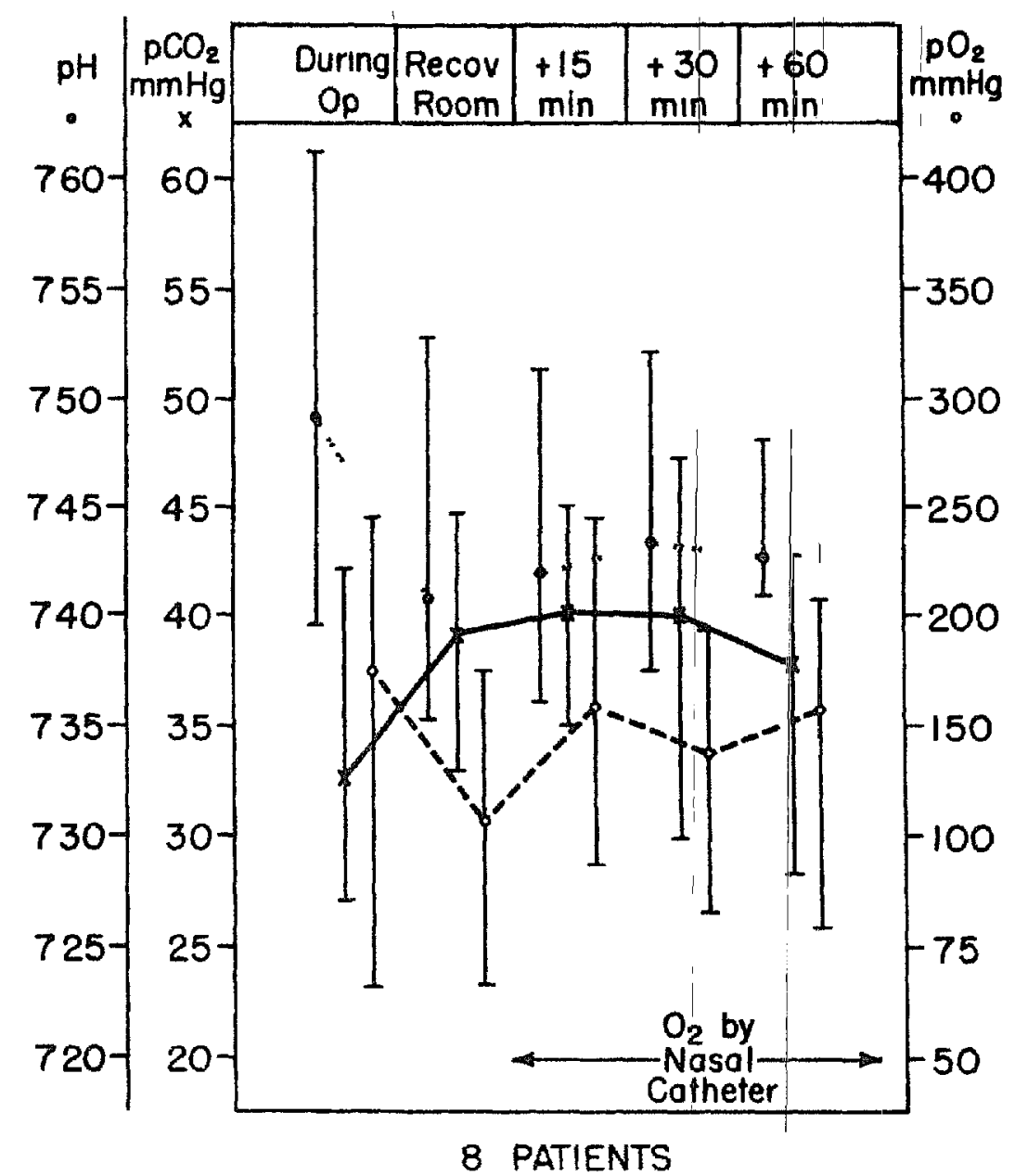

Figure $9 \mathrm{pH}, \mathrm{paCO}_{2}$, and $\mathrm{paO}_{2}$ values obtained in eight patients during anaesthesia and for 60 minutes postoperatively Oxygen given by nasal catheter Note normal acid-base balance and satısfactory oxygen tensions

The oxygen tension values obtained in the recovery room were broken down into age groups In patients over 50 years of age who breathed only room air in the recovery room, the $\mathrm{paO}_{2}$ was consistently just over $60 \mathrm{~mm} \mathrm{Hg}$ (Fig 10) When patients of this age group were given oxygen by mask, more than adequate oxygen tensions were attained, however, with oxygen by nasal catheter, barely satisfactory tensions were found ( $F_{1}$ 11) In the age group under 50 years breathing room arr, more adequate oxygen tensions were attained, but the average fell short of the "normal" (Fig 12) However, the administration of oxygen to this group resulted in high oxygen tensions, even when administration was by nasal catheter ( $F_{1} g$ 13)

\section{Discussion}

The conclusions to be derived from this study are few but significant (1) The "normal" arterial oxygen tension is unknown and may vary from one person to another, depending on his physical status and age (2) The administration of anaesthesia and the performance of surgery lead to a state of arterial hypoxaemia in the immediate postoperative period (3) The reduction in arterial oxygen tension exists in the presence of a minute volume gas exchange which usually is sufficient to maintain a normal pH and arterial carbon dioxide tension (4) The administration of oxygen postoperatively serves to correct the arterial hypoxaemia 
satisfactorily in most patients It is obvious, then, that all patients should receive oxygen following administration of general anaesthesia

The natural question which arises is why patients become hypoxaemic following anaesthesia and operation The first thoughts that come to mind are the apparent ones associated with respuratory depression following the use of anaesthetic drugs postoperative pain limiting respiratory exchange, or unusual positions in the operating room leading to inadequate ventilation These factors cannot be iuled out, and one or more of them may play a part in individual patients However, in this group of patients, minute volume and tidal volume exchange did not differ significantly in the lesting preoperative and postoperative periods Also, parenthetically, there was great variation in the resting preoperative oxygen tension values

The fact that arterial oxygen tensions were lower in the older age group leads to the possibility that diffusion defects across the alveolar membrane may be responsible for the hypoxaemia Rame and $B_{1 s h o p}{ }^{3}$ doubt that this explanation is valid However, it has yet to be iuled out

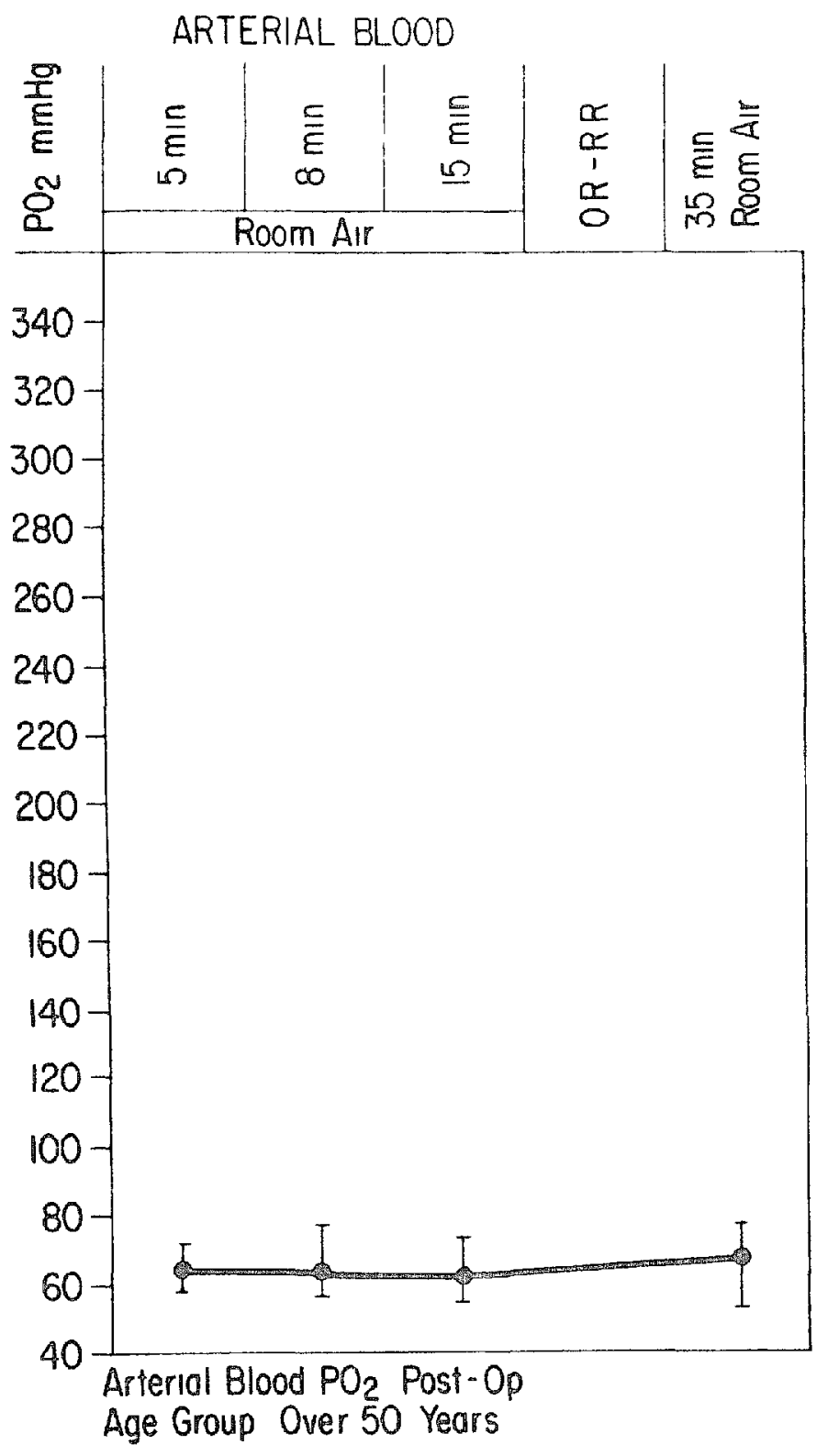

Figure 10 Postoperative oxygen tensions in patients over 50 years of age who breathed room air in recovery room

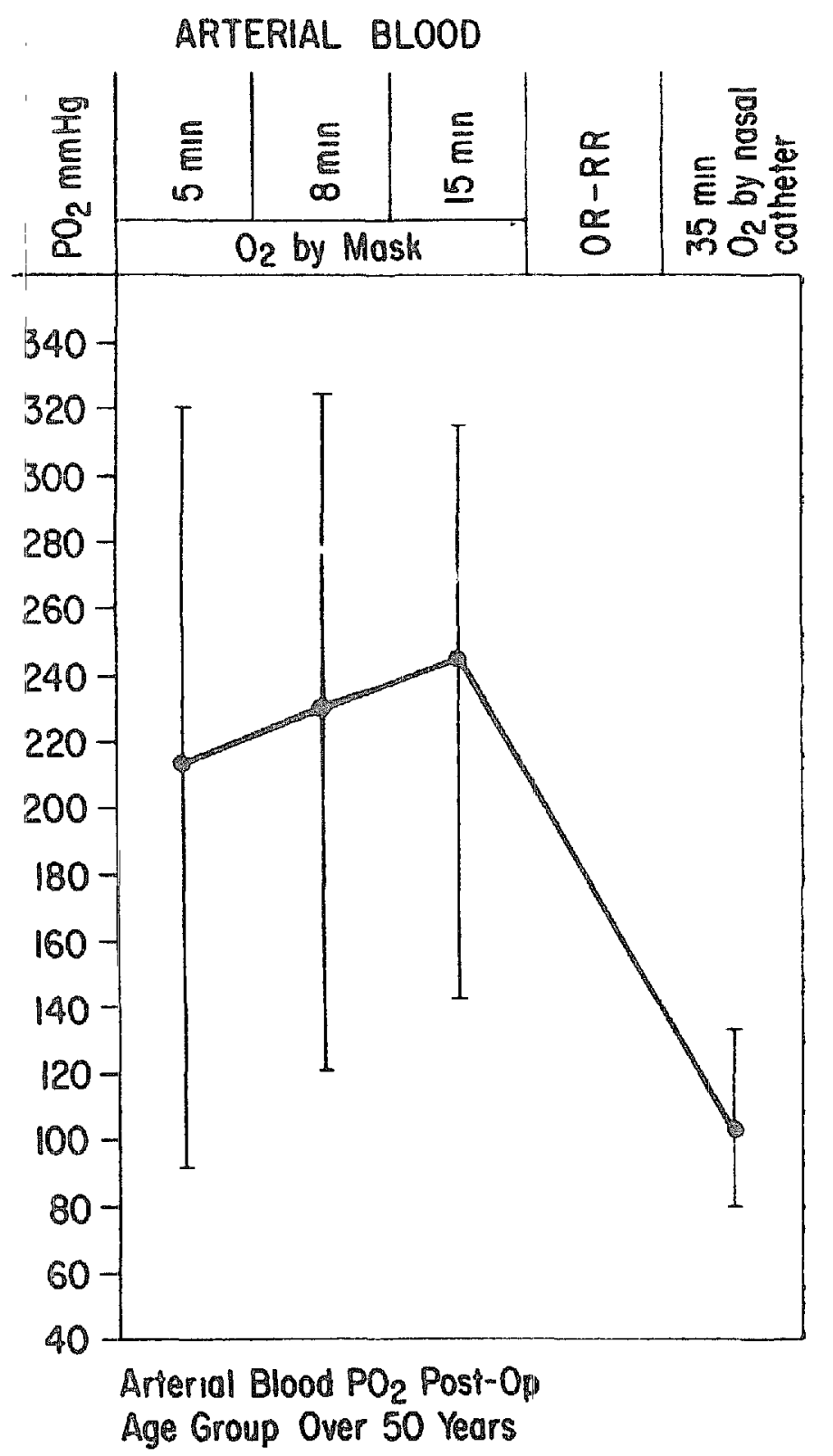

Figure 11 Postoperative oxygen tensions in age group over 50 who breathed first oxygen by mask and then recenved oxygen by nasal catheter Note relatively low oxygen tensions associated with nasal catheter administration 


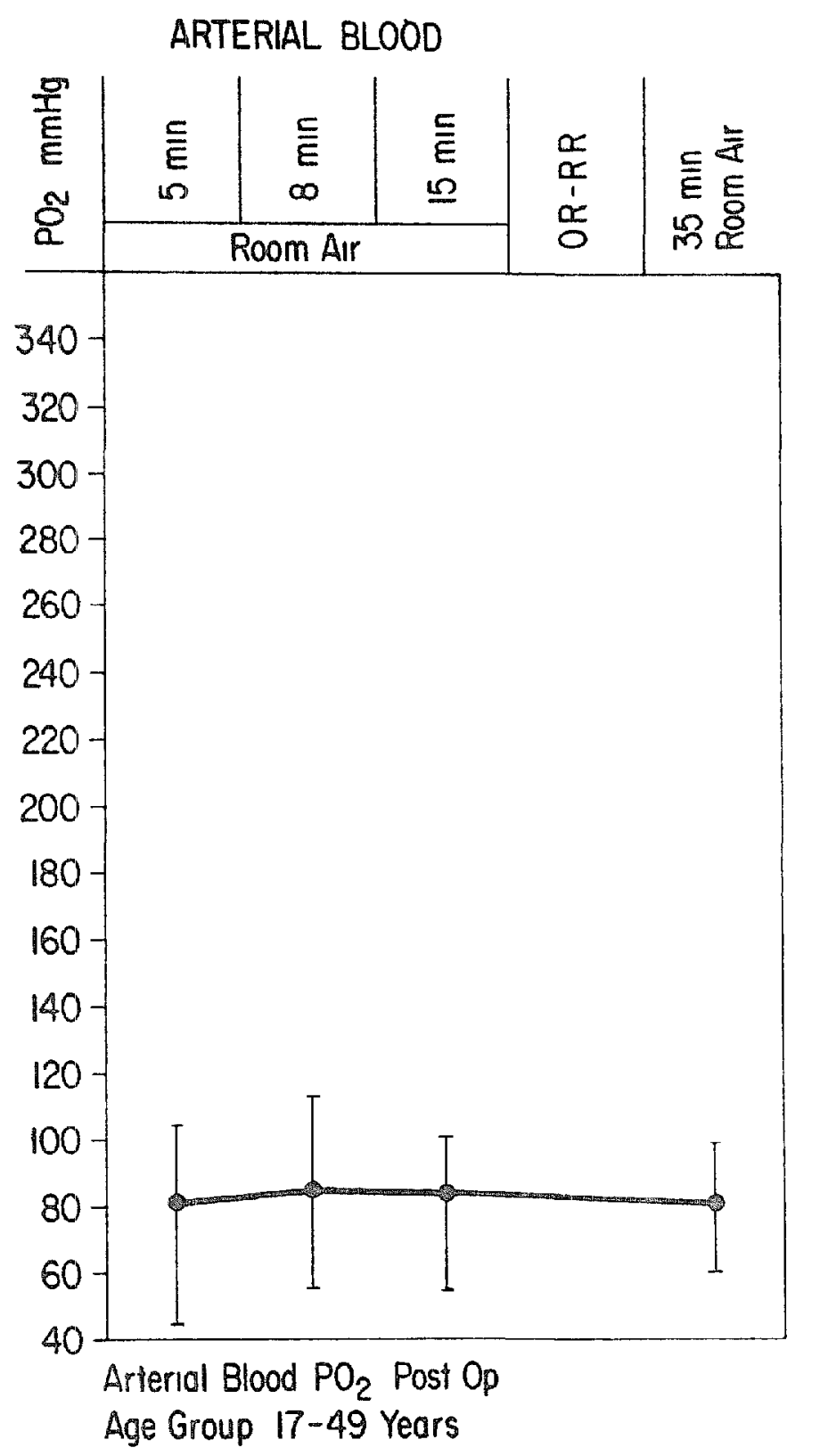

FIGURE 12 Postoperative oxygen tensions in age group under 50 years who breathed room aur in recovery room
ARTERIAL BLOOD

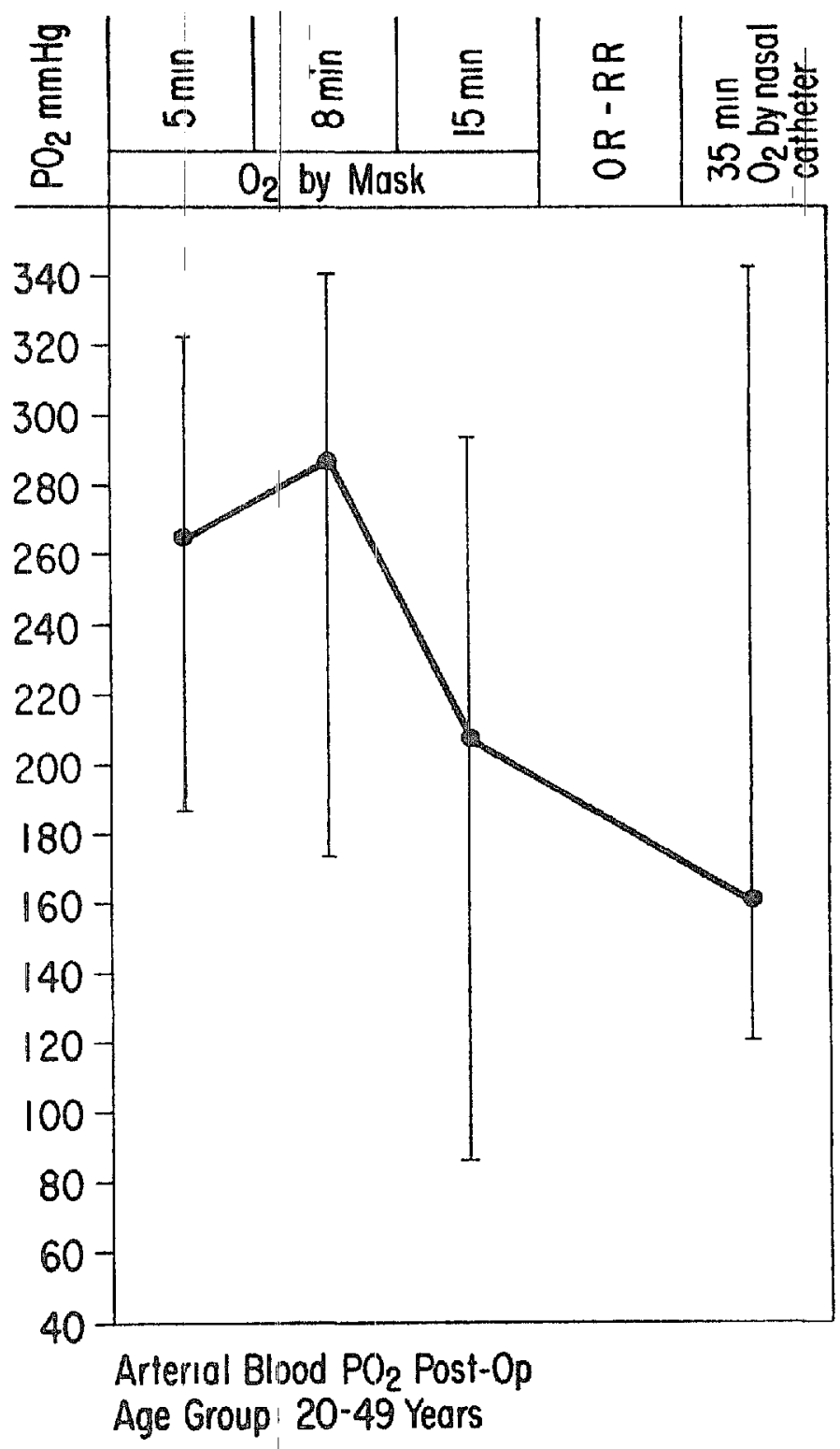

Figure 13 Postoperative oxygen tensions in patients under 50 years of age who received oxygen Note satisfactory values at all times

Benduxen and colleagues, ${ }^{1}$ who have noted consistent reductions in arterial oxygen tension during and after procedures in which patients have been ventilated with "normal" tidal volumes, believe that the hypoxaemia results from small, miliary areas of atelectasis that develop during the course of consistent tidal ventilation They hypothesize that, unless deep sighing respirations are provided, as the awake person does involuntarlly every few minutes, physiological shunts develop through which blood flows, but which cannot become oxygenated because of the surrounding atelectatic alveoli A similar situation could occur in the recovery room, of course, where the patient cannot or will not take deep breaths In this respect, the old therapy of carbon dioxide inhalations to promote deep breathing may have real merit At the present time, analeptic drugs are being investigated as pharmacologic stimulants to promote deep bi eathing postoperatively ${ }^{5}$

Perhaps the most widely accepted explanation for the arterial hypoxaemia is that an alteration occurs in the ventilation-perfusion ratios between gas and perfusing blood in the lungs ${ }^{6,7}$ In older patients with chest disease, if is recognized that inequality of ventilation-perfusion ratios is the commonest cause of arterial oxygen 
unsaturation It is more than likely that certain techniques of anaesthesia may also disturb the ventilation-perfusion ratio It is known that, during normal spontaneous ventilation, most of the mhaled gas goes to the lower lobes of the lungs through which most of the blood is flowng The diaphragm plays a vital part in this movement of gas During controlled respiration, with the diaphragm quiet, a greater proportion of the gas being pushed in goes to the upper parts of the lung, thus upsetting the ventilation-perfusion ratio

Arterial hypoxaemia may also result from increases in physiological dead space, which alter the ventilation-perfusion ratio Hypotension increases the physiological dead space, and the administration of ethyl ether and halothane, by some mechanısm as yet unknown, also increases this parameter

Tamlın et al $^{8}$ have recently implicated atıopıne as a cause of arterial hypoxaemia, although they offer no reasons for therr belief A possible explanation would be on the basis of atropine increasing physiological dead space The findings reported in their paper are not too convincing, in that the oxygen tensions were derived indirectly, the ages of the patients were not taken into consideration, and the variations noted in the oxygen tensions of patients with and without administration of atropine were not marked

It is apparent that the cause of arterial hypoxaemia in the postoperative period is uñknown it may be a summation of several factors in some patients Nor is the duration of this abnormality known Much information remains to be collected and interpreted one predicts that, with the newer laboratory techniques now avalable, great activity will be seen in this area in the next 10 years

\section{SUMMARY}

1 The present concept that the "normal" arterial oxygen tension is $100 \mathrm{~mm}$ $\mathrm{Hg}$ may have to be altered In patients being prepared for elective surgical procedures, the average oxygen tension was $804 \mathrm{~mm} \mathrm{Hg}$

2 In the immediate postoperative period, arterial hypoxaemia was present in all patients who were allowed to breathe room air At the same time, the $\mathrm{pH}$ and carbon dioxide tensions of the arterial blood were within normal limits

3 Patients in the age group over 50 showed greater degrees of arterial hypoxaemia than those under 50

4 The administration of oxygen by mask or nasal catheter postoperatively corrected the low arterial oxygen tensiops All patients should receive oxygen in the postoperative period

5 The most likely explanation tor the asterial hypoxaemia is a disturbance in the ventilation-perfusion ratio in the lungs

\section{RÉ@UMÉ}

1 Il faut changer le concept actuel que la tension "normale" de l'oxygène artériel est de $100 \mathrm{~mm}$ de mercure Chez les malades préparés pour la chirurgie électıve, la tension moyenne de l'oxygène était de $804 \mathrm{~mm}$ de mercure

2 Durant la période postopératorre immédıate, $11 \mathrm{y}$ avait de lhypoxémie 
artérielle chez tous les malades qui respiraient l'air de la pièce Au même moment, le $\mathrm{pH}$ et les tensions d'acıde carbonıque du sang artériel se tenaient dans les imites de la normale

3 Les malades de plus de 50 ans ont présenté une hypoxémıe artérielle plus mportante que ceux de moins de 50 ans

4 L'administration d'oxygène par masque ou cathéter nasal a corrigé les basses tensions d'oxygène artériel Tous les malades devrarent recevoir de l'oxygène durant la période postopér atorre

5 L'explication la plus vraisemblable de cette hypoxémıe artérıelle est qu'il se produt un trouble dans le rapport ventilation-perfusion dans les poumons

\section{ACKNOWLEDGMENTS}

Gratitude is expressed to Mr Ray Andrews for technical help and to the Recovery Room nurses for their constant co-operation

This work was supported in part by a grant from the $\mathbf{A} \mathbb{H}$ Robins Co, Richmond, Virginia

\section{REFERENCES}

1 Driprs, R D \& Waters, R M Nursing Care of Surgical Patients The "Stir-up" Am I Nursing 41 (May, 1941)

2 Lambertsen, C J Gas Exchanges of the Atmosphere, Lungs and Blood Chapter 36, Medical Physiology, edited by P Bard St Lous C V Mosby (1961)

3 Ranne, I $M$ \& Bishop, J $M$ A-a Difference in $\mathrm{O}_{2}$ Ten;ion and Physiological Dead Space in Normal Man J Appl Physiol 18 284-288 (May 1963)

4 Bendixen, $\mathrm{H}$ H, Hedley-Whyte, $J$, \& LAVER, $\mathrm{M}$ B Imparred Oxygenation in Surgical Patients during General Anaesthesia with Controlled Ventilation New Engl J. Med 269 991-996 (1963)

5 Stephen, C R \& Talton, I Investigation of Doxapram as a Postanesthetic Respiratory Stimulant Anesth \& Analg (in press)

6 Conway, $\mathrm{C} M$ \& Payne, J $\mathrm{P}$ Post-operative Hypoxaemia and Oxygen Therapy Brit Med J 1 844-845 (1963)

7 West, J B Blood-Flow, Ventilation, and Gas Exchange in the Lung Lancet 11 1055-1058 (1963)

8 Tamlin, $\mathbb{Y}$ J, Conway, C M, \& Payne, J $\mathbb{P}$ Hypoxaemich due to Atropine Lancet 1 14-16 (1964) 